\title{
Predictors of Outcome in Patients with Cervical Spondylotic Myelopathy Undergoing Unilateral Open-Door Laminoplasty
}

\author{
Ji-Won Shin, Sung-Won Jin, Se-Hoon Kim, Jong-ll Choi, Bum-Joon Kim, \\ Sang-Dae Kim, Dong-Jun Lim \\ Department of Neurosurgery, Ansan Hospital, Korea University College of Medicine, Ansan, Korea
}

\begin{abstract}
Objective: This study aimed to analyze prognostic factors affecting surgical outcomes of expansive laminoplasty for cervical spondylotic myelopathy (CSM).

Methods: Using the Frankel scale and Japanese Orthopaedic Association (JOA) scale, we retrospectively reviewed the outcomes of 45 consecutive patients who underwent modified unilateral open-door laminoplasty using hydroxyapatite spacers and malleable titanium miniplates between June 2008 and May 2014. The patients were assigned to the good and poor clinical outcome groups, with good outcome defined as a JOA recovery rate $>75 \%$.

Results: The mean preoperative JOA scale was significantly higher in the good outcome group $(14.95 \pm 3.21$ vs. $10.78 \pm 6.07$, $p<0.001)$, whereas the preoperative cervical range of motion $(R O M)$ in this group was significantly lower $\left(29.89^{\circ} \pm 10.11\right.$ vs. $44.35^{\circ} \pm 8.88, p<0.001$ ). In univariate analysis, a high preoperative JOA scale (odds ratio (OR) $1.271,95 \%$ confidence interval (Cl) 1.005-1.607) and low preoperative cervical ROM (OR 0.858, 95\% Cl 0.786-0.936) were statistically correlated with good outcomes. Furthermore, these factors demonstrated an independent association with clinical outcomes (preoperative JOA scale: OR 1.344, 95\% Cl 1.019-1.774, $\mathrm{p}=0.036$; preoperative cervical ROM: OR 0.860, 95\% Cl 0.788-0.940, $\mathrm{p}=0.001$ ). Conclusion: In this study, a high preoperative JOA scale was associated with good clinical outcome after laminoplasty, whereas a higher preoperative cervical spine ROM was associated with poor clinical outcome. This may suggests that cervical mobility and preoperative neurological status affect clinical outcomes of laminoplasty.
\end{abstract}

Key Words: Myelopathy $\cdot$ Cervical spondylosis $\cdot$ Ossification $\cdot$ Posterior longitudinal ligament $\cdot$ Laminoplasty $\cdot$ Prognosis

\section{INTRODUCTION}

Cervical spondylotic myelopathy (CSM) is a condition in which compression of the spinal cord results from degenerative changes and spine instability. Two main causes of this condition are cervical spondylosis (CS) and ossification of the posterior longitudinal ligament (OPLL) ${ }^{20)}$. Although typically symptoms appear without obvious predisposing factors and progress slowly, CSM is triggered by trauma and advances rapidly in some cases. Conservative treatment is rarely successful in ameliorating the symptoms or decelerating disease

- Received: November 3, 2015 • Revised: November 29, 2015

- Accepted: December 2, 2015

Corresponding Author: Se-Hoon Kim, MD, PhD

Department of Neurosurgery, Ansan Hospital, Korea University College of Medicine, 123 Jeokgeum-ro, Danwon-gu, Ansan, Gyeonggi-do 15355, Korea

Tel: +82-31-412-5050, Fax: +82-31-412-5054

E-mail: sehoonkim.ns@gmail.com

@This is an Open Access article distributed under the terms of the Creative Commons Attribution Non-Commercial License (http://creativecommons.org/ licenses/by-nc/3.0/) which permits unrestricted non-commercial use, distribution, and reproduction in any medium, provided the original work is properly cited. progression, and therefore immediate surgical intervention is of crucial importance ${ }^{1)}$.

After the introduction of laminoplasty by Hirabayashi in 1977, expansive laminoplasty (EL) has become an attractive treatment option for cervical spondylotic myelopathy ${ }^{10)}$. Thus, EL has been deemed a superior alternative to laminectomy or laminectomy and fusion for patients with cervical myelopathy as it may decrease the incidence of progressive spinal deformity and prevent the need for subsequent spinal stabilization when compared with laminectomy ${ }^{2)}$.

Many authors have reported satisfactory surgical outcomes of laminoplasty for CSM. However, there is still some controversy concerning the prognostic factors. Therefore, the purpose of this study was to analyze various prognostic factors that could impact the surgical outcomes of EL.

\section{MATERIALS AND METHODS}

\section{Study Population}

We retrospectively reviewed the outcomes of 45 consecutive patients who underwent modified unilateral open-door 
laminoplasty using hydroxyapatite (HA: HOYA Corporation PENTAX, Tokyo, Japan) spacers and malleable titanium miniplates (Fig. 1) ${ }^{12)}$ between June 2008 and May 2014. The subjects were 36 men and 9 women aged from 38 to 78 years (mean 55.64 years). CS was present in 29 patients and OPLL was present in 16 patients. Twenty-two patients had a history of trauma and 23 patients showed symptoms of cord compression without a definite history of trauma. From patients with a history of trauma, only those without prior fracture or dislocation of the cervical spine were selected for the study. The mean follow-up duration was 20.55 months (range 12-81 months).

\section{Clinical Outcome Evaluation}

Patient's neurological status was evaluated using the Frankel scale immediately before the surgery and at the final visit. In this scale, the maximum score is " $\mathrm{E}$ " (normal motor and sensory function) and the minimum score is " $\mathrm{A}$ " (absent motor and sensory function $)^{3)}$. We utilized a scale of 1 to $5(1=\mathrm{A}$, $2=\mathrm{B}, 3=\mathrm{C}, 4=\mathrm{D}$, and $5=\mathrm{E})^{12}$. The presence of myelopathy was assessed using the Japanese Orthopaedic Association (JOA) scale immediately before the surgery and at the final postoperative visit. In this scale, the maximum score is 17 and the minimum score is 0 . Rate of recovery from myelopathy at the final postoperative visit was calculated using the formula [(Final postoperative visit JOA scale - JOA scale immediately before surgery)/(17 - JOA scale immediately before surgery) $] \times 100^{9)}$. We defined good clinical outcome as a JOA recovery rate greater than $75 \%$, and the patients were divided into two groups (good vs. poor outcome).

\section{Radiologic Outcome Evaluation}

Radiologic evaluations of the cervical spine included plain radiographs before the surgery and 1, 2, 4, 6 and 12 months after the surgery to obtain the average Pavlov ratio at operated

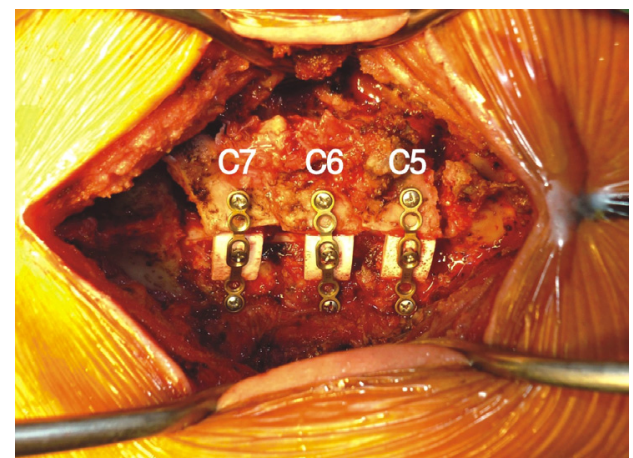

Fig. 1. Intraoperative photo of three-level unilateral open-door laminoplasty. laminae (canal-body ratio) and curvature of the cervical spine (Cobb's method of drawing a line parallel to the inferior aspect of the $\mathrm{C} 2$ body and a line parallel to that of the $\mathrm{C} 7$ body on a true lateral plain radiograph) ${ }^{18,14)}$. The range of motion (ROM) was calculated as the sum of cervical angles in maximal flexion and extension on a true lateral plain radiograph (Fig. 2). Rates of loss of cervical curvature and ROM were obtained using the following formulae $\mathrm{e}^{22)}$ :

Loss of lordosis $(\%)=$ (preoperative cervical curvature - final visit cervical curvature)/(preoperative cenvical curvature) $\times 100 \%$

Loss of cervical spine ROM (\%)=(preoperative ROM - final visit $\mathrm{ROM}) /$ (preoperative cervical curvature) $\times 100 \%$

Three-dimensional computed tomography (3-D CT) was performed preoperatively and 12 months after the surgery to detect any implant-related complications. In addition, magnetic resonance $(\mathrm{MR})$ imaging was conducted preoperatively and 12 months after the surgery to evaluate the cervical spine and assess expansion of the dural sac and decompression of the spinal cord.

\section{Statistical Analysis}

Candidate prognostic factors were compared between the good and poor outcome groups with the Mann-Whitney Utest for continuous variables and Pearson's chi-square test for categorical variables. Independent associations between prognostic factors and clinical outcomes were analyzed using binary logistic regression, and odds ratio (OR) and their 95\% confidence interval (CI) were calculated. All results were expressed as mean \pm standard deviation (SD). Analyses were per-
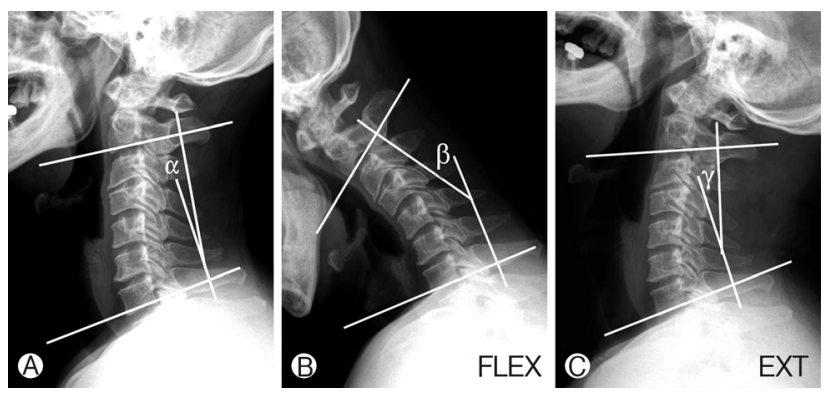

Fig. 2. A schematic illustration of the method of measurement of cervical curvature and range of motion (ROM) of the cervical spine in plain radiographs. We utilized Cobb's method, which includes drawing a line parallel to the inferior aspect of the C2 body and a line parallel to that of the $\mathrm{C} 7$ body in a true lateral plain radiograph in the neutral $(A)$, maximum flexion $(B)$, and maximum extension $(C)$ positions. The angle in the neutral position is termed "cervical curvature" (a), and the sum of cervical curvatures at maximum flexion $(\beta)$ and maximum extension $(\gamma)$ is termed "ROM". 
formed using the IBM Statistical Package for the Social Sciences, version 18.0 (SPSS Inc., Chicago, IL).

\section{RESULTS}

The demographics of the 45 patients who underwent modified unilateral open-door laminoplasty using HA spacers and malleable titanium miniplates are summarized in Tables 1 and 2. The overall mean age was $55.64 \pm 8.02$ years, and there were $36(80 \%)$ men and $9(20 \%)$ women. CS was present in $29(64 \%)$ patients, and OPLL was present in $16(36 \%)$ patients. Twenty-two (49\%) patients had a history of trauma, and 23
(51\%) patients showed symptoms of cord compression without a history of trauma. Fourteen patients received 4-level laminoplasty and 31 patients received 3-level laminoplasty.

The overall mean Frankel score improved from 3.93 to 4.53, and the mean JOA scale increased from 12.82 to 14.82 (Table 1). The mean calculated recovery rate was $67.00 \pm$ 33.99\% (Table 2).

Radiologic data were obtained in the 45 patients who were followed up for more than 12 months postoperatively. Postoperative MR imaging revealed adequate expansion of the dural sac and decompression of the spinal cord in all the patients (Fig. 3A, B). Postoperative 3-D CT demonstrated reconstructed laminae in appropriate positions (Fig. 3C). There

Table 1. Patient factors of modified unilateral laminoplasty in cervical spondylotic myelopathy

\begin{tabular}{|c|c|c|c|c|}
\hline Clinical characteristics & All patients $(n=45)$ & Good outcome $(n=22)$ & Poor outcome $(n=23)$ & $\mathrm{p}$-value \\
\hline Age (years) & $55.64 \pm 8.02$ & $57.55 \pm 6.57$ & $53.83 \pm 8.96$ & $0.080^{*}$ \\
\hline $\operatorname{Sex}(n)$ & & & & $0.655^{* *}$ \\
\hline Male & 36 & 17 & 19 & \\
\hline Female & 9 & 5 & 4 & \\
\hline Trauma History (n) & & & & $0.458^{* *}$ \\
\hline$(+)$ & 22 & 12 & 10 & \\
\hline$(-)$ & 23 & 10 & 13 & \\
\hline Type of diagnosis (n) & & & & $0.912^{* *}$ \\
\hline CS & 29 & 14 & 15 & \\
\hline OPLL & 16 & 8 & 8 & \\
\hline Number of laminoplasty levels ( $\mathrm{n}$ ) & & & & $0.235^{* *}$ \\
\hline 3 & 31 & 17 & 14 & \\
\hline 4 & 14 & 5 & 9 & \\
\hline \multicolumn{5}{|l|}{ Frankel scale } \\
\hline Preoperative & $3.93 \pm 1.27$ & $4.00 \pm 1.15$ & $3.87 \pm 1.39$ & $0.981^{*}$ \\
\hline Final & $4.53 \pm 0.69$ & $4.68 \pm 0.48$ & $4.39 \pm 0.84$ & $0.288^{*}$ \\
\hline \multicolumn{5}{|l|}{ JOA scale } \\
\hline Preoperative & $12.82 \pm 5.27$ & $14.95 \pm 3.21$ & $10.78 \pm 6.07$ & $<0.001^{*}$ \\
\hline Final & $14.82 \pm 3.94$ & $16.77 \pm 0.87$ & $12.96 \pm 4.78$ & $<0.001^{*}$ \\
\hline \multicolumn{5}{|l|}{ Pavlov ratio } \\
\hline Preoperative & $0.74 \pm 0.09$ & $0.73 \pm 0.09$ & $0.74 \pm 0.10$ & $0.817^{*}$ \\
\hline Final & $0.99 \pm 0.14$ & $0.97 \pm 0.14$ & $1.03 \pm 0.13$ & $0.248^{*}$ \\
\hline \multicolumn{5}{|l|}{ Curvature $\left({ }^{\circ}\right)$} \\
\hline Preoperative & $15.02 \pm 7.18$ & $15.43 \pm 8.11$ & $14.63 \pm 6.33$ & $0.892^{*}$ \\
\hline Final & $9.69 \pm 6.40$ & $9.80 \pm 6.32$ & $9.57 \pm 6.61$ & $0.919^{*}$ \\
\hline \multicolumn{5}{|l|}{ Cenvical spine $\operatorname{ROM}\left({ }^{\circ}\right)$} \\
\hline Preoperative & $37.28 \pm 11.90$ & $29.89 \pm 10.11$ & $44.35 \pm 8.88$ & $<0.001^{*}$ \\
\hline Final & $23.39 \pm 11.61$ & $16.44 \pm 7.43$ & $30.03 \pm 11.07$ & $<0.001^{*}$ \\
\hline
\end{tabular}

CS: Cervical spondylosis, OPLL: Ossification of the Posterior Longitudinal Ligament, JOA: Japanese Orthopaedic Association, ROM: Range of Motion

"Mann-Whitney U-test, "** Pearson's chi-squaretest 
were no implant-related complications such as breakdown or dislocation of HA implants or delayed dural laceration. Followup plain radiography and 3-D CT revealed proper fusion and stability of the reconstructed laminae in all the patients.

The overall cervical ROM decreased from $37.28 \pm 11.90^{\circ}$ to $23.39 \pm 11.61^{\circ}$ after the surgery (Table 1$)$. The loss of cervical ROM was $37.09 \pm 22.27 \%$ (Table 2). The lordotic curvature of the cervical spine decreased from $15.02 \pm 7.18^{\circ}$ to 9.69 $\pm 6.40^{\circ}$ (Table 1). The loss of lordosis was $36.32 \pm 25.60 \%$ (Table 2). However, there were no instances of postoperative kyphotic deformity. The Pavlov ratio improved from 0.74 \pm 0.09 to $0.99 \pm 0.14$ (Table 1 ).

\section{Patient-related Factors}

Age and sex were not statistically associated with clinical outcomes ( $\mathrm{p}=0.080$ and 0.655 , respectively; Mann-Whitney U-test for age distribution and Pearson's chi-square test for sex distribution). Similarly, there were no statistically significant associations between clinical outcomes and diagnosis, presence of trauma history, and number of laminoplasty levels $(p=0.912,0.458$, and 0.235 , respectively; Pearson's chisquare test).
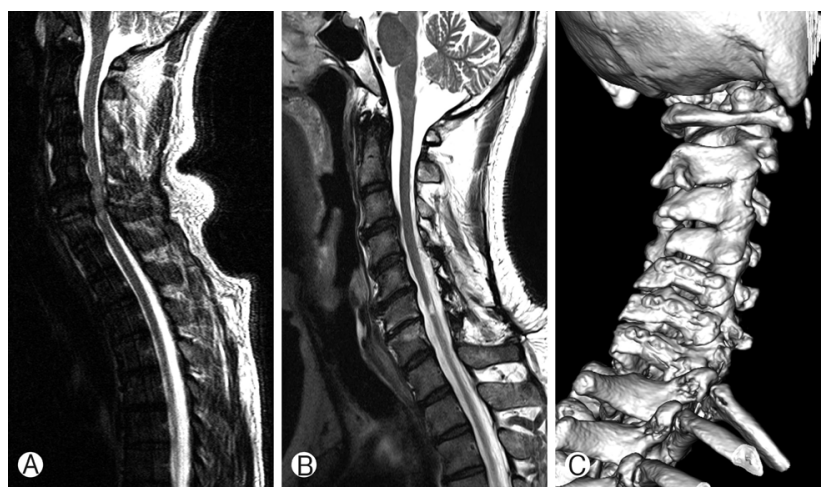

Fig. 3. A representative case of modified unilateral open-door laminoplasty at C5, C6, and C7 using hydroxyapatite spacers and miniplates. (A) and (B) preoperative and postoperative magnetic resonance images, respectively; $(C)$ a follow-up 3-D computed tomography scan.

Table 2. Clinical and radiologic results of 45 patients who underwent modified unilateral laminoplasty

\begin{tabular}{lc}
\hline \hline Clinical characteristics & All patients $(n=45)$ \\
\hline Recovery rate of JOA scale (\%) & $67.00 \pm 33.99$ \\
Loss of lordosis (\%) & $36.32 \pm 25.60$ \\
Loss of Cervical spine ROM (\%) & $37.09 \pm 22.27$ \\
\hline
\end{tabular}

JOA: Japanese Orthopaedic Association, ROM: Range of Motion

\section{Clinical Factors}

The preoperative Frankel scores did not differ between the two groups ( $\mathrm{p}=0.981$, Mann-Whitney U-test). However, there was a significant difference in the preoperative JOA scale $(14.95 \pm 3.21$ in the good outcome group vs. $10.78 \pm 6.07$ in the poor outcome group $[\mathrm{p}<0.001$, Mann-Whitney U-test $]$ ).

\section{Radiologic Factors}

The preoperative cervical ROM was significantly greater in the poor clinical outcome group than in the good clinical outcome group $\left(44.35^{\circ} \pm 8.88\right.$ and $29.89^{\circ} \pm 10.11$, respectively $[\mathrm{p}<0.001$, Mann-Whitney U-test] $)$. In contrast, other factors, such as preoperative Pavlov ratio and preoperative cervical curvature, were not statistically associated with clinical outcomes ( $\mathrm{p}=0.817$ and 0.892 , respectively, Mann-Whitney U-test).

We did not found implant-related complications in any case documented during the follow-up period, and there existed no space between bone edge of lamina and HA spacer on 3-D CT.

\section{Evaluation of Prognostic Factors}

Tables 3 and 4 present the results of logistic regression analysis of associations between the characteristics and clinical outcomes. Univariate analysis revealed that, among the candidate factors, increased preoperative JOA scale (OR 1.271, 95\% CI 1.005-1.607) and decreased preoperative cervical ROM (OR 0.858, 95\% CI 0.786-0.936) were statistically correlated with good outcomes of patients who underwent laminoplasty for CSM (Table 3). These factors were also independently asso-

Table 3. Result of univariate analysis

\begin{tabular}{lccc}
\hline \hline \multirow{2}{*}{ Clinical characteristics } & \multicolumn{3}{c}{ Univariate study } \\
\cline { 2 - 4 } & OR & $95 \% \mathrm{Cl}$ for OR & p-value \\
\hline Preoperative JOA scale & 1.271 & $1.005-1.607$ & 0.045 \\
Preoperative Cervical $\mathrm{ROM}\left({ }^{\circ}\right)$ & 0.858 & $0.786-0.936$ & 0.001 \\
\hline JOA: Japanese Orthopaedic Association, ROM: Range of Motion
\end{tabular}

Table 4. Result of multivariate analysis

\begin{tabular}{lccc}
\hline \hline \multirow{2}{*}{ Clinical characteristics } & \multicolumn{3}{c}{ Multivariate study } \\
\cline { 2 - 4 } & OR & $95 \%$ Cl for OR & p-value \\
\hline Preoperative JOA scale & 1.344 & $1.019-1.774$ & 0.036 \\
Preoperative Cervical ROM $\left({ }^{\circ}\right)$ & 0.860 & $0.788-0.940$ & 0.001 \\
\hline JOA: Japanese Orthopaedic Association, ROM: Range of Motion
\end{tabular}


ciated with clinical outcomes (preoperative JOA scale: OR 1.344, 95\% CI 1.019-1.774, $\mathrm{p}=0.036$; preoperative cervical ROM: OR 0.860, 95\% CI 0.788-0.940, $\mathrm{p}=0.001$ ) (Table 4). Other factors, such as age, sex, history of trauma, diagnosis, number of laminoplasty levels, preoperative Frankel score, preoperative Pavlov ratio, and preoperative cervical curvature showed no significant associations with clinical outcomes.

\section{DISCUSSION}

The overall average recovery rate in the patients who underwent our modified unilateral open-door laminoplasty using hydroxyapatite spacers and miniplates was $67 \%$ as assessed using the JOA scale, and there were no cases with complications or late neurologic deterioration during the mean followup period of 20.55 months.

CSM causes severe disability in the elderly more often than in middle-age patients ${ }^{21)}$. Some authors have investigated the relationship between age and surgical outcomes of laminoplasty. The results suggested that old age is associated with poor clinical outcome ${ }^{1,13)}$. In this regard, atherosclerotic changes in the feeding vascular structures are a common condition in older patients. For this reason, cervical spondylosis and cord ischemia occur frequently in this age group ${ }^{14}$. Although other authors also reported surgical outcomes of laminoplasty in elderly patients, their conclusions were controversial ${ }^{11,19)}$. In the present study, there was no relation between age and clinical outcome. It is possible, however, that our patients were too young for such an association to be identified.

Many authors also suggested that good preoperative JOA scale correlated with satisfactory surgical outcomes. Thus, Hamburger et al. ${ }^{7)}$ described a relationship between preopera tive clinical condition and surgical outcomes, which was especially strong for preoperative JOA scale $\geq 10$. Furthermore, Handa et al. ${ }^{8)}$ reported that severity of preoperative symptoms significantly $(\mathrm{p}<0.05)$ influenced clinical outcome in their younger ( $<70$ years of age) group. In agreement with the results of these studies, we found that preoperative JOA scale predicted neurological recovery.

In agreement with the findings of a previously published report, our modified surgical technique significantly improved the expansion of the narrow cervical spinal canal $35.37 \%$ improvement in the Pavlov ratio determined as [final visit Pavlov ratio - preoperative Pavlov ratio]/[preoperative Pavlov ratio] $\times$ $100 \%$ ) without causing any complications ${ }^{12}$. Several reports demonstrated the existence of a relationship between anteroposterior spinal cord diameter and clinical outcome $e^{1,4,5,13)}$. Thus, according to Fujiwara et al. ${ }^{6}$, results of surgical treatment of CSM are associated with anteroposterior diameter of the cervical spinal canal. In our study, however, there was no statistically significant association between Pavlov ratio and clinical outcome.

Recent reports described mobility and segmental stability of the cervical spine as an important dynamic factor. According to Masaki et al. ${ }^{15)}$, segmental ROM at the level of the most severe cord compression was significantly greater in the poor clinical outcome group, and anterior cervical discectomy and fusion was recommended for those patients. Ogawa et al. ${ }^{17)}$ also reported a relationship between preoperative C2-7 ROM and late deterioration in OPLL patients. Cervical mobility had an overall effect on clinical outcomes of laminoplasty in OPLL patients. Our study included both CS and OPLL patients. Nevertheless, we found that preoperative C2-7 ROM correlated with clinical outcome. We suggest that CS is similar to OPLL in that ischemia and repeated direct trauma of the spinal cord due to flexion-extension movement play a role in the pathophysiology of progressive cord injury ${ }^{16}$.

This study is limited by the small number of patients and retrospective data collection. In addition, the postoperative follow-up period may not have been long enough to assess potential neurologic deterioration. Furthermore, changes in spinal cord signal intensity were not evaluated as a predictive factor for clinical outcome of laminoplasty. Further prospective randomized study with a larger sample and longer followup period is required to confirm the specific relationships between prognostic factors and clinical outcomes described in this study.

\section{CONCLUSION}

Various prognostic factors of laminoplasty outcomes in patients with CSM have been described. A higher preoperative JOA scale had a significant relationship with good clinical outcomes after modified unilateral open-door laminoplasty using HA spacers and miniplates. Furthermore, a greater preoperative cervical spine ROM was associated with poor clinical outcomes of laminoplasty. These results suggest that cervical mobility and preoperative patient neurologic status may affect clinical outcomes of laminoplasty.

\section{REFERENCES}

1. Ahn JS, Lee JK, Kim BK: Prognostic factors that affect the surgical outcome of the laminoplasty in cervical spondylotic myelopathy. Clin Orthop Surg 2:98-104, 2010

2. Della Pepa GM, Roselli R, La Rocca G, Spallone A, Barbagallo G, Visocchi M: Laminoplasty is better of laminectomy in cervical 
stenotic myelopathy: myth or truth? Eur Rev Med Pharmacol Sci 18:50-54, 2014

3. Frankel HL, Hancock DO, Hyslop G, Melzak J, Michaelis LS, Ungar GH, et al: The value of postural reduction in the initial management of closed injuries of the spine with paraplegia and tetraplegia. I. Paraplegia 7:179-192, 1969

4. Fujimura Y, Nishi Y, Nakamura M: Dorsal shift and expansion of the spinal cord after expansive open-door laminoplasty. J Spinal Disord 10:282-287, 1997

5. Fujiwara K, Yonenobu K, Ebara S, Yamashita K, Ono K: The prognosis of surgery for cervical compression myelopathy. An analysis of the factors involved. J Bone Joint Surg $\mathrm{Br}$ 71:393398, 1989

6. Fujiwara K, Yonenobu K, Hiroshima K, Ebara S, Yamashita K, Ono K: Morphometry of the cervical spinal cord and its relation to pathology in cases with compression myelopathy. Spine (Phila Pa 1976) 13:1212-1216, 1988

7. Hamburger C, Büttner A, Uhl E: The Cross-sectional area of the cervical spinal canal in patients with cervical spondylotic myelopathy: Correlation of preoperative and postoperative area with clinical symptoms. Spine (Phila Pa 1976) 22:1990-1994, 1997

8. Handa Y, Kubota T, Ishii H, Sato K, Tsuchida A, Arai Y: Evaluation of prognostic factors and clinical outcome in elderly patients in whom expansive laminoplasty is performed for cervical myelopathy due to multisegmental spondylotic canal stenosis. A retrospective comparison with younger patients. J Neurosurg 96:173179, 2002

9. Hirabayashi K, Satomi K: Operative procedure and results of expansive open-door laminoplasty. Spine (Phila Pa 1976) 13:870876, 1988

10. Hirabayashi K, Watanabe K, Wakano K, Suzuki N, Satomi K, Ishii Y: Expansive open-door laminoplasty for cervical spinal stenotic myelopathy. Spine (Phila Pa 1976) 8:693-699, 1983

11. Ishii M, Wada E, Ishii T, Kawai H, Kaneko N, Fuji T: Laminoplasty for patients aged 75 years or older with cervical myelopathy. J Orthop Surg (Hong Kong) 16:211-214, 2008

12. Jin SW, Kim SH, Kim BJ, Choi JI, Ha SK, Kim SD, et al: Modified Open-door Laminoplasty Using Hydroxyapatite Spacers and Miniplates. Korean J Spine 11:188-194, 2014

13. Kohno K, Kumon Y, Oka Y, Matsui S, Ohue S, Sakaki S: Evaluation of prognostic factors following expansive laminoplasty for cervical spinal stenotic myelopathy. Surg Neurol 48:237-245, 1997

14. Kwon SY, Shin JJ, Lee JH, Cho WH: Prognostic factors for surgical outcome in spinal cord injury associated with ossification of the posterior longitudinal ligament (OPLL). J Orthop Surg Res 10:94, 2015

15. Masaki Y, Yamazaki M, Okawa A, Aramomi M, Hashimoto M, Koda M, et al: An analysis of factors causing poor surgical outcome in patients with cervical myelopathy due to ossification of the posterior longitudinal ligament: anterior decompression with spinal fusion versus laminoplasty. J Spinal Disord Tech 20: 7-13, 2007

16. Mattei TA, Goulart CR, Milano JB, Dutra LPF, Fasset DR: Cervical spondylotic myelopathy: pathophysiology, diagnosis, and surgical techniques. ISRN Neurol 2011:463729, 2011

17. Ogawa Y, Chiba K, Matsumoto M, Nakamura M, Takaishi H, Hirabayashi $\mathrm{H}$, et al: Long-term results after expansive opendoor laminoplasty for the segmental-type of ossification of the posterior longitudinal ligament of the cervical spine: a comparison with nonsegmental-type lesions. J Neurosurg Spine 3:198204, 2005

18. Ogino H, Tada K, Okada K, Yonenobu K, Yamamoto T, Ono $\mathrm{K}$, et al: Canal diameter, anteroposterior compression ratio, and spondylotic myelopathy of the cervical spine. Spine (Phila Pa 1976) 8:1-15, 1983

19. Suzuki A, Misawa H, Simogata M, Tsutsumimoto T, Takaoka K, Nakamura H: Recovery process following cervical laminoplasty in patients with cervical compression myelopathy: prospective cohort study. Spine (Phila Pa 1976) 34:2874-2879, 2009

20. Wang MC, Kreuter W, Wolfla CE, Maiman DJ, Deyo RA: Trends and variations in cervical spine surgery in the United States: Medicare beneficiaries, 1992 to 2005. Spine (Phila Pa 1976) 34:955-961, 2009

21. Yamazaki T, Yanaka K, Sato H, Uemura K, Tsukada A, Nose T: Cervical spondylotic myelopathy: surgical results and factors affecting outcome with special reference to age differences. Neurosurgery 52:122-126, 2003

22. Yeh KT, Chen IH, Yu TC, Liu KL, Peng CH, Wang JH, et al: Modified expansive open-door laminoplasty technique improved postoperative neck pain and cervical range of motion. J Formos Med Assoc 2014 (Epub ahead of print) 